Disponível em:

http://editora.unoesc.edu.br/index.php/race

Race, Joaçaba, v. 14, n. 3, p. 889-904, set./dez. 2015

\title{
AGRICULTURA FAMILIAR E PRODUÇÃO DE BIODIESEL: UMA ANÁLISE NO NORTE MATO-GROSSENSE
}

\section{Family farming and biodiesel production: an analysis in northern Mato Grosso}

Marcos Rodrigues

E-mail:marcos.rodrigues.adm@gmail.com

Mestre em Agronegócios e Desenvolvimento Regional pela Universidade Federal do Mato Grosso (UFMT). Doutorando em Desenvolvimento Socioambiental pela Universidade Federal do Pará (UFPA). Endereço para contato: Avenida Perimetral, 1, Guamá, 66075-750, Belém, PA, Brasil.

Artigo recebido em 25 de fevereiro de 2015. Aceito em 28 de maio de 2015. 
Resumo

A produção de biodiesel no Mato Grosso desenvolveu-se rapidamente a partir da implantação do Programa Nacional de Produção e Uso do Biodiesel (PNPB) e, com ela, a demanda por matéria-prima de origem da agricultura familiar. Objetivou-se, com este estudo, verificar se as políticas de inclusão social do PNPB estão sendo efetivas no norte mato-grossense. A partir da coleta de informações com produtores rurais familiares distribuídos por quatro municípios do norte mato-grossense que fornecem matéria-prima para a produção de biodiesel, foi possível identificar que existe um predomínio do cultivo de soja para atender aos requisitos do Programa, e mesmo com as limitações existentes para a soja na agricultura familiar, os produtores são capazes de desempenhar essa atividade dadas as suas condições de capital. Por meio da Análise Envoltória de Dados (DEA), também foi possível comparar a eficiência dos produtores, identificando que grande parte deles possui uma boa eficiência em relação à renda e à produção.

Palavras-chave: Agricultura familiar. Biodiesel. Desenvolvimento rural.

\title{
Family farming and biodiesel production: an analysis in northern Mato Grosso
}

\author{
Abstract
}

Biodiesel production in Mato Grosso developed quickly since the implementation of the National Biodiesel Use and Production Program (PNPB) and with it, the demand for raw material source of family farming. The objective with this study was to verify if the social inclusion policies of PNPB are being effective in Northern Mato Grosso. From the collection of information with family farmers who are spread over four municipalities of northern Mato Grosso that provide raw material for biodiesel production, it was identified that there is a predominance of soybean cultivation to meet the program requirements, and even with the limitations for soybeans in family farming, the producers are able to perform this activity given their conditions of capital. Through Data Envelopment Analysis (DEA), was also possible to compare the efficiency of producers, identifying that most of them has a good efficiency in relation to income and production.

Keywords: Family farming. Biodiesel. Rural development.

\section{INTRODUÇÃO}

Seguindo uma agenda mundial em relação a mudanças energéticas, o Brasil inseriu oficialmente em sua matriz o biodiesel a partir de 2005, por meio do Programa Nacional de Produção e Uso do Biodiesel (PNPB). A questão ambiental, 
apesar de ter um enfoque importante dentro do contexto da produção de biodiesel, não é o único fator responsável pelo desenvolvimento dessa atividade no país.

Com o Programa foram desenvolvidas outras duas bases, uma econômica, que se reflete no desenvolvimento e crescimento de um novo setor produtivo, que foi capaz de, em poucos anos, demonstrar o seu grande potencial produtivo, aproveitando óleos vegetais que já eram produzidos no contexto nacional e gerando novos setores industriais em diversas regiões do País. A outra base foi o contexto social, no qual, com o programa, se buscou, mediante a inserção da agricultura familiar como fornecedora de matéria-prima para o setor, gerar emprego e renda no campo, principalmente para um segmento produtivo social que ficou (e ainda fica) excluído da plena participação no mercado.

Assim, foi criado o Selo Combustível Social, instrumento de intervenção estatal no setor privado, que proporciona vantagens competitivas e fiscais para as empresas que adquirirem o percentual mínimo de aquisição de matéria-prima oriunda da agricultura familiar. Esta, por sua vez, além de ter a oportunidade de adentrar economicamente em uma atividade voltada para o mercado, fazendo uso da terra e gerando renda para a família, recebe algumas vantagens, como bônus de aquisições, insumos, assistência técnica, acesso ao crédito, entre outros. Delgado (2009, p. 18) coloca que "[...] a intervenção do Estado na agricultura tem uma longa tradição [...] e seu objetivo fundamental tem sido regular os mercados agrícolas, garantindo preços e rendas para os agricultores.”

A soja, no contexto mato-grossense, é uma cultura de alto grau de modernização, em que grandes volumes de capital são aplicados (seja na forma de insumos seja de produtos e equipamentos agrícolas), portanto, possui uma taxa menor de lucro, o que apenas viabiliza a cultura quando obtidos retornos de escala, ou seja, nas grandes propriedades monocultoras. Assim, fica estabelecido um problema para a cadeia de biodiesel: estaria o PNPB realmente sendo capaz de cumprir sua função social em integrar a agricultura familiar no fornecimento de matérias-primas conforme planejado e ao mesmo tempo manter um ambiente competitivo entre as usinas produtoras?

Objetivou-se, com este estudo, verificar se a produção de soja pela agricultura familiar no Mato Grosso é capaz de atingir aos objetivos de melhoria de vida e geração de renda a partir da comercialização de commodities agrícolas para a produção de biodiesel. Também realizou-se uma análise da eficiência entre os produtores rurais pesquisados por meio do uso da Análise Envoltória de Dados (DEA). 


\section{PERSPECTIVAS ACERCA DO DESENVOLVIMENTO RURAL}

Para Prado Junior (1987), o processo de colonização brasileiro foi determinante para caracterizar a atual estrutura fundiária. Originou-se um modelo concentrador de terras no qual se viabiliza a produção primária (cana-de-açúcar, café), surgindo os latifúndios e reduzindo a capacidade de desenvolvimento de um mercado para comercialização da produção da pequena propriedade. Na estrutura do Mato Grosso, as commodities assumem esse papel de ser um produto primário, visto que grande parcela da produção de soja é destinada à exportação, portanto, a "exclusão" da agricultura familiar desse mercado foi baseada em critérios econômicos de eficiência e de capital (formando o ganho de escala e possibilitando a rentabilidade desses produtos agrícolas), que suprimiram alternativas de desenvolvimento baseadas na pequena propriedade.

A perspectiva de que a agricultura se transformou em um setor dependente da indústria é apresentada por Guimarães (1982), em que ela acaba dependendo tanto pelo lado do fornecimento de insumos e equipamentos necessários para o cultivo e produção, quanto no aspecto da comercialização, principalmente quando da aquisição da produção pelas empresas ligadas ao agronegócio (tradings). Em uma agricultura altamente tecnificada e dependente de capital como é a produção de soja no Mato Grosso, a cadeia acaba se verticalizando, envolvendo ainda mais os produtores com os compradores de sua produção e, ao mesmo tempo, com os fornecedores de insumo, criando tanto uma dependência, quanto uma relação de longo prazo.

Batalha e Silva (2011) colocam que a produção agrícola não pode mais ser tratada em questão de agentes individuais, mas sob toda a cadeia produtiva, que engloba desde a produção, a transformação, a distribuição e o consumo. Esse arranjo, denominado complexo agroindustrial, tem início desde a produção da matériaprima agrícola (inclusive pelo setor anterior à produção, como o fornecimento de equipamentos e insumos) até as diversas formas de processamento e beneficiamento dessa matéria-prima. O complexo agroindustrial do biodiesel tem em sua cadeia a agroindústria de óleo vegetal como intermediária entre a matéria-prima e a produção de biodiesel, responsável pela produção do óleo vegetal (LIMA; CASTRO, 2010a).

A produção agrícola sofre um processo de modernização constante, no qual novos métodos de produção, máquinas e equipamentos são incorporados à estrutura produtiva, contribuindo para o aumento significativo da produção, mas, em contrapartida, também cresce o montante de investimento (capital) para sua 
execução. Tal estrutura apenas pode ser mantida com ganhos cada vez maiores de escala, que são proporcionados em grandes extensões de terras, ou seja, apenas em uma produção latifundiária, excluindo do processo de modernização boa parte da agricultura familiar que não dispõe de capital (ou acesso a ele) suficiente para acompanhar as transformações que ocorrem. Esse incremento na exigência de investimento tende a diferenciar ainda mais a capacidade produtiva entre a pequena e a grande produção agrícola. Assim, o pequeno produtor rural, muitas vezes desprovido de conhecimento, capacitação e capital suficiente, acaba se submetendo a trabalhos penosos, de baixo nível técnico e, muitas vezes, com uma renda baixa; abandona a atividade da terra e passa à condição de trabalhador, mesmo que das propriedades vizinhas (SILVA, 1978).

Schultz (1965) emprega o conceito de agricultura tradicional para explicar a existência da pobreza e baixa renda no ambiente rural. Para ele, a agricultura tradicional é caracterizada por aquela que resiste a mudanças tecnológicas ocorridas no decorrer do tempo, logo, sua produção é executada de formas, muitas vezes, rudimentares e acaba sendo incapaz de produzir muitos excedentes comercializáveis. Para tanto, o autor propõe que tal agricultura deve adotar novos "fatores" de produção, como insumos, sementes melhoradas, espécies mais resistentes ou novas técnicas e equipamentos, para, dessa forma, manter-se competitiva; soma-se, ainda, o fato da necessidade da disseminação do conhecimento, por meio da educação e extensão rural, pois também ao produtor é necessário passar o conhecimento sobre como utilizar os novos fatores, caso contrário, tornam-se obsoletos, pois realizar a poupança para investimento em fatores já utilizados, a exemplo dos tradicionais, não é suficiente para promover a geração de renda.

A pesquisa experimental e o desenvolvimento de novas técnicas e instrumentos para produção, quando realizados por empresas particulares, objetivam basicamente o lucro. Dadas as especificidades da agricultura, tais pesquisas restringem-se (em muitos casos) à grande produção, pois ali o volume produzido (e consequentemente o lucro destas empresas) é maior. Nesse sentido, é importante a presença do Estado ou de empresas sem fins lucrativos como provedoras de pesquisas que atendem à exigência e à demanda da pequena propriedade, a qual diverge da grande tanto em tipo de produto quanto no montante de aplicação de capital (que vai além de aplicações materiais) e de trabalho (SCHULTZ, 1965).

A pobreza rural é evidente na América Latina; De Janvry e Sadoulet (2000) colocam que ela representava cerca de $30 \%$ da pobreza total. Os autores identificam quatro caminhos para a redução da pobreza, a saída do campo, com a preparação dos 
jovens para trabalhos não rurais, a produção agrícola, a pluriatividade e a assistência. Destacam o papel da tecnologia como forma de aumento da produtividade e renda, e, nesse sentido, o crédito rural e as políticas públicas (como o PNPB) podem promover a inclusão no mercado e a modernização das atividades rurais de pequenas propriedades.O clássico artigo de Johnston e Mellor (1961) contribui para o debate da importância da agricultura como forma de desenvolvimento econômico para economias subdesenvolvidas, colocando que, muitas vezes, por ser menos dependente de capital diante da indústria, ela existe em maior proporção nesses países, portanto, também contribui em maior parte para a renda nacional e o emprego. Ela também contribui para o desenvolvimento como uma das principais fontes de exportação e geração de divisas, a formação de capital para o investimento no setor industrial e a transferência de mão de obra do campo para outras atividades em desenvolvimento. Políticas públicas devem orientar esse processo de desenvolvimento a partir do aumento da produtividade agrícola.

\section{O PNPB E A PRODUÇÃO DE MATÉRIAS-PRIMAS PELA AGRICULTURA FAMILIAR}

O considerável aumento da emissão de poluentes, principalmente pela queima de combustíveis fósseis (petróleo, gás natural, carvão), considerados os principais causadores de danos ambientais, como o aquecimento global. Tal situação se agravou com o aumento da produção industrial, que também acelerou a emissão desses poluentes em razão do uso mais intensivo de energia, provocando questionamentos quanto à sustentabilidade do modelo produtivo. Portanto, nesse cenário, os biocombustíveis ganharam espaço na produção energética pelo fato de serem renováveis e menos poluentes em decorrência da compensação de carbono pela utilização de matérias-primas oriundas da biomassa (HOUTART, 2010).

$O$ biodiesel foi introduzido na matriz energética brasileira a partir da promulgação da Lei n. 11.097, de 13 de janeiro de 2005. Nela ficou estabelecido que o percentual mínimo a ser adicionado ao diesel, após três anos da publicação da legislação, seria de $2 \%$ em volume, atingindo o percentual de $5 \%$ até o final de oito anos. Entretanto, o Programa foi capaz de, observado o nível de produção e assimilação do setor com a produção, em janeiro de 2010, já ter sido alcançada a marca de adição de $5 \%$ de biodiesel ao diesel. Após um longo período sem mudanças, em julho de 2014, o percentual de adição subiu para 6\% e, logo em seguida, em 
novembro, para 7\%. A produção anual de biodiesel no Brasil cresceu de $736 \mathrm{~m}^{3}$, em 2005, para, em 2013, atingir a marca de $2.917 .488 \mathrm{~m}^{3}$, crescimento este que demonstra o sucesso que o setor obteve no decorrer de quase uma década de sua participação na matriz energética brasileira. Os dados para a produção anual por região encontram-se na Tabela 1.

Tabela 1 - Evolução da produção de biodiesel (B100) nas regiões brasileiras e no Brasil (mil m³) - 2005 a 2013

\begin{tabular}{lrrrrrrrrr}
\hline $\begin{array}{l}\text { Re- } \\
\text { gião }\end{array}$ & $\mathbf{2 0 0 5}$ & $\mathbf{2 0 0 6}$ & $\mathbf{2 0 0 7}$ & $\mathbf{2 0 0 8}$ & $\mathbf{2 0 0 9}$ & $\mathbf{2 0 1 0}$ & $\mathbf{2 0 1 1}$ & $\mathbf{2 0 1 2}$ & $\mathbf{2 0 1 3}$ \\
\hline Brasil & 0,74 & 69,00 & 404,33 & $1.167,13$ & $1.608,45$ & $2.386,40$ & $2.672,76$ & $2.717,48$ & $2.917,49$ \\
$\begin{array}{l}\text { Norte } \\
0,51\end{array}$ & 2,42 & 26,59 & 15,99 & 41,82 & 95,11 & 103,45 & 78,65 & 62,24 \\
$\begin{array}{l}\text { Nor- } \\
\text { deste }\end{array}$ & 0,16 & 34,80 & 172,20 & 125,91 & 163,91 & 176,99 & 176,42 & 293,57 & 278,38 \\
$\begin{array}{l}\text { Sudes- } \\
\text { te }\end{array}$ & 0,04 & 21,56 & 37,02 & 185,59 & 284,77 & 420,33 & 379,41 & 255,73 & 261,37 \\
$\begin{array}{l}\text { Sul } \\
\begin{array}{l}\text { Cen- } \\
\text { tro- } \\
\text {-Oeste }\end{array}\end{array}$ & 0,03 & 0,10 & 42,71 & 313,35 & 477,87 & 675,67 & 976,93 & 926,61 & $1.132,41$ \\
Fonte: Agência Nacion & 10,12 & 125,81 & 526,29 & 640,08 & $1.018,30$ & $1.036,56$ & $1.162,91$ & $1.183,09$ \\
\hline
\end{tabular}

Fonte: Agência Nacional do Petróleo (2014).

As maiores produções de biodiesel localizam-se na região Sul, com destaque para o Estado do Rio Grande do Sul, e para a região Centro-Oeste, principalmente Goiás e Mato Grosso. Essas duas regiões representaram juntas 79,37\% da produção nacional em 2013. Osaki e Batalha (2011) ressaltaram em seu estudo o crescimento da produção de biodiesel na região Centro-Oeste, pelo fato de este ter uma grande oferta de oleaginosas em razão da produção agrícola (assim como a região Sul), entretanto, advertem acerca dos riscos na oferta de óleo vegetal pela grande dependência da produção de soja, que está sujeita a diversas variações de preço e produção.

Para Castro, Lima e Pinheiro (2010), o preço da matéria-prima é fundamental na opção pelo processo industrial realizado pelas usinas (conforme os autores, os custos da matéria-prima representam aproximadamente $80 \%$ dos custos totais de fabricação). Portanto, aquelas cadeias produtoras de matéria-prima com maior eficiência, estrutura organizacional e capacidade de fornecimento contínuo serão afirmadas como as grandes fornecedoras para as indústrias (lugar hoje ocupado principalmente pelo óleo de soja). As vantagens em relação à soja são a elevada escala de produção existente no país, o que assegura uma regularidade no fornecimento de matéria-prima para o complexo industrial do biodiesel, o elevado aumento 
de produtividade da matéria-prima que ocorre pela mecanização da produção e aplicação de fertilizantes químicos, e a organização da cadeia, evidenciada pelo desempenho do produto no mercado (LIMA; CASTRO, 2010b).

Em razão da pequena escala de produção e das necessidades de capital, agricultores familiares acabam sendo restringidos da produção de soja, exceto se tiverem como desenvolver essa atividade em sua propriedade, limitando um grande contingente de produtores rurais dada a grande pobreza no meio rural brasileiro, como demonstrado por Finco, Ribeiro e Bailis (2014) em sua análise em Tocantins.

Embora a produção de biodiesel tenha surgido como uma prática que visava à redução de emissão de gases causadores do efeito estufa (e também a geração de renda na agricultura familiar, no caso do Brasil), consequências ambientais, como a substituição de áreas de floresta por áreas de monocultura e debates sobre a segurança alimentar, como na agricultura familiar, que é um grande fornecedor de alimentos, são agora colocados para reavaliar a viabilidade dos biocombustíveis para a sociedade e também para encontrar soluções para esses problemas (FARGIONE; PLEVIN; HILL, 2010; GRAHAM-ROWE, 2011).

\section{METODOLOGIA}

O estudo de caso foi realizado com produtores familiares que fornecem matéria-prima para a produção de biodiesel para uma usina localizada no norte do Estado de Mato Grosso. Ao todo, foram entrevistados 25 produtores, localizados nos Municípios de Feliz Natal, Nova Ubiratã, Tabaporã e Vera, todos em Mato Grosso e com características fundiárias e de colonização muito silimilares. Também são municípios que tiveram projetos de assentamento implantados durante a década de 1990, e parte desses produtores assentados fazem parte da amostra selecionada.

Em relação à receita total obtida, os resultados foram atualizados por meio do IPCA para o mês de maio de 2013, conforme a data de realização do contrato e a negociação de preços entre o produtor e a usina; o período de pesquisa abrangendo aquisições de matéria-prima das safras foi 2010/2011, 2011/2012 e 2012/2013.

Para a mensuração da eficiência dos produtores rurais, foi utilizada como metodologia a Análise Envoltória de Dados (Data Envelopment Analysis (DEA)). Esse método é baseado em programação matemática para mensurar a eficiência de unidades produtivas que utilizem múltiplos inputs e outputs. O modelo considerado 
para análise neste trabalho é o modelo BCC, que considera rendimentos variáveis de escala (Equação 1).

$$
\begin{array}{ll}
\text { Max } h_{0} \text {, sujeito a: } & \\
& x_{i o}-\sum_{k=1}^{n} x_{i k} \lambda_{k} \geq 0, \forall i \\
& -h_{0} y_{j o}+\sum_{k=1}^{n} y_{j k} \lambda_{k} \geq 0, \forall j \\
& \sum_{k=1}^{n} \lambda_{k}=1 \\
& \lambda_{k} \geq 0, \forall k
\end{array}
$$

Onde representa os inputs utilizados por cada DMU (Decision Making Unit) e é o resultado (output) obtido por cada DM; é o vetor de pesos e determina a presença de rendimentos variáveis ou constantes de escala. Os inputs utilizados para a análise foram a área total plantada pelo produtor, a experiência na atividade, os anos de estudo e o crédito rural. Como outputs, foram selecionados a produção total em sacas do produto e a receita total obtida pela venda dos produtos.

\section{RESULTADOS E DISCUSSÃO}

Analisando os resultados obtidos com a pesquisa de campo, nota-se uma heterogeneidade quanto à posse da terra. Primeiramente, é possível perceber a integração de produtores rurais localizados em assentamentos da região, demonstrando que a busca de produtores rurais pelas usinas de biodiesel se estende aos assentamentos rurais, frequentemente com condições precárias de crédito, assistência técnica e infraestrutura de transporte. Apenas 28\% dos entrevistados não eram assentados e possuíam terra própria ou arrendada, portanto, uma prática já observável do PNPB é a capacidade em movimentar empresas para viabilizar a integração de segmentos antes restringidos no mercado agrícola, visto que o Programa também estabelece que as empresas devem prestar assistência técnica aos produtores familiares.

Para os produtores que possuem titulação própria, estes possuem a propriedade próxima à sede municipal, portanto, possuem menos dificuldade de tráfego em relação àqueles que residem no assentamento, contrariamente ao produtor que possui a área arrendada, localizada muito próxima ao assentamento Califórnia, em Vera, portanto, utiliza as mesmas vias de acesso (em Vera, as condições de tráfego 
são mais satisfatórias em relação aos demais municípios, o que favorece a aquisição de produtos desse município, além de facilitar a viabilidade da produção agrícola).

Todos os produtores entrevistados possuem Declaração de Aptidão ao Programa Nacional de Fortalecimento da Agricultura Familiar (Pronaf) (DAP), haja vista que tal documento é obrigatório para a comercialização de matéria-prima para a produção de biodiesel na usina. Entretanto, nem todos possuem acesso ao crédito Pronaf, 14 produtores (56\%) afirmaram obter recursos por meio do Pronaf, enquanto os demais produtores não operam por essa linha de crédito. Ainda, desses 14 produtores que obtiveram acesso à linha de crédito, 11 fazem parte de assentamento, ou seja, obtiveram uma linha de crédito rural específica para o caso. Os demais, por não estarem na condição de assentados, possuíam à sua disposição linhas de crédito capazes de oferecer melhor suporte à produção de soja (como o Pronaf mais alimentos).

A soja é a principal oleaginosa utilizada para a produção de biodiesel no País e no Mato Grosso. Portanto, todos os produtores entrevistados a fornecem como matéria-prima, a qual, por sua vez, é amplamente questionada quanto à sua rentabilidade na produção da agricultura familiar, considerando-se a sua condição em relação à área disponível para cultivo e aos altos investimentos necessários, que criam a necessidade da adoção de economias de escala para rentabilizar a cultura da soja.

Entretanto, nas discussões iniciais e no início do Programa, um ponto crucial para a plena integração da agricultura familiar foi a questão de qual matériaprima seria fornecida. Dessa forma, ficou planejada a diversificação desta, conforme o contexto regional no qual estaria inserido o produtor. Mas não foi exatamente dessa forma que se desenvolveu o mercado de produção de biodiesel, e os fatos são claros para essa compreensão.

O óleo de soja e o sebo bovino hoje são os principais produtos utilizados como matéria-prima para a produção de biodiesel. São produtos que se originam dentro de duas cadeias produtivas fortemente verticalizadas, em que poucas empresas detêm uma parcela significativa da produção regional (ou mesmo nacional), e tais matérias-primas surgem com subprodutos dentro de sua atividade principal. Enquanto as tradings agrícolas adquirem a soja para exportação ou fabricação de farelo e os frigoríficos buscam a carne bovina como principal produto, o sebo e o óleo de soja, produzidos em grande escala em razão da grande quantidade de produto processado, transformam-se em biodiesel.

Nesse mesmo contexto, outras empresas atuam simplesmente com a produção de biodiesel como atividade-fim (e única). São usinas formadas com essa 
finalidade e desligadas da cadeia da soja, e algumas outras podem ser consideradas usinas pequenas, tanto em capacidade produtiva, quanto em capital investido. Fica formado, assim, o setor altamente oligopolizado, no qual algumas matérias-primas dominam a produção de biodiesel e, consequentente, vão impactar diretamente o produtor familiar.

Alguns fatores foram determinantes para a viabilização dessa produção na agricultura familiar a partir dos resultados coletados nas entrevistas. $O$ investimento em capital fixo é reduzido, pois aquisições de máquinas pesadas e equipamentos são restritos a alguns itens, como tratores e pulverizadores de pequeno porte. Colheitadeiras, plantadeiras e outras máquinas são arrendadas de prestadores de serviço da região a um custo mais baixo em razão de a área de execução da atividade ser pequena (com raras exceções, alguns produtores possuíam esses equipamentos, embora de fabricação mais antiga conseguiam realizar esse serviço em pequenas propriedades com eficiência). As especificações de qualidade de entrega do produto seguem o mesmo formato a todos os produtores; a prestação da assistência técnica orienta a aquisição de insumos, produtos e sementes especificadas para o plantio por esses produtores, assim, obtém-se uma produtividade satisfatória, capaz de cobrir custos de plantio e de gerar renda. Observa-se, também, que, como a soja é uma cultura de ganhos de escala, os produtores que possuem maiores extratos de terra (e, portanto, cultivam em maior área) obtêm, também, maiores receitas. Assim, dentro da própria agricultura familiar, existe uma diferença de rendimentos baseada principalmente na extensão das terras, observando-se que as técnicas de cultivo são similares entre os produtores.

Em valores atualizados, a maior e a menor receita obtida ocorreram na mesma safra (2010/2011), com um total aproximado de R \$ 167.300,00 e de R \$ 58.090,00, respectivamente (rendimento médio de $\mathrm{R} \$ 77.945,00)$. O aumento do rendimento médio para as safras de 2011/2012 (R\$ 99.634,00) ocorreu principalmente pelo aumento do preço da soja no período, que se estendeu até a safra 2012/2013 (R\$ 115.205,00). Portanto, os produtores também estão sujeitos a variações nos preços do produto. Como é um segmento com menor poder econômico e disponibilidade de capital, variações significativas quanto à redução do preço da soja podem impactar diretamente na viabilidade da cultura e na geração de renda, embora mecanismos tenham sido assimilados ao PNPB para reduzir parte da flutuação de renda, como o pagamento obrigatório de bônus de R \$ 1,20 por saca de soja quando de origem da agricultura familiar, o que contribui para a maior capacidade de formação de renda. 
Para analisar a eficiência entre os produtores rurais, utilizou-se DEA, considerando quatro inputs e dois outputs pelo modelo BBC orientado a outputs, visando maximizar os retornos de produção e a receita dos produtores familiares. Os resultados obtidos estão descritos no Gráfico 1, por classe de eficiência.

Gráfico 1 - Distribuição dos produtores familiares por classe de eficiência por meio da DEA

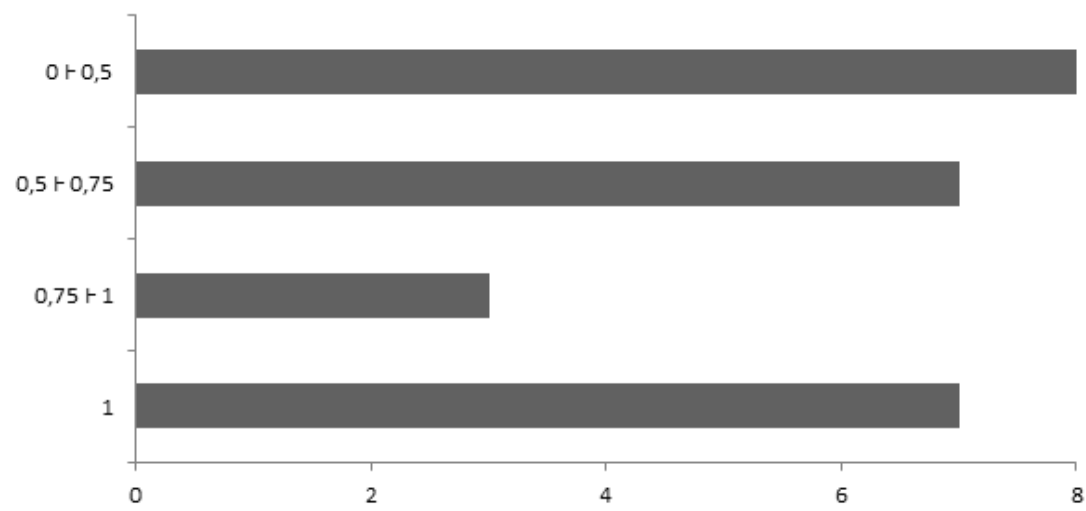

Fonte: os autores.

Comparar a eficiência entre os produtores familiares de soja para o PNPB permite verificar quais unidades apresentam melhor utilização dos fatores. Percebese que a maioria dos produtores possui uma eficiência razoável ou boa (resultados maiores que 0,5 ), enquanto outros ficam na faixa da ineficiência (resultados menores que 0,5$)$.

O PNPB ainda necessita de evolução em sua política de incentivo à produção familiar de matérias-primas para o biodiesel. Uma das restrições observadas na pesquisa foi que o crédito rural acaba sendo um dos poucos instrumentos que permitem a capitalização dos produtores. As empresas que adquirem a matéria-prima dos produtores acabam por fornecer insumos e condições mais favoráveis para esses produtores por meio da negociação antecipada da safra, para, assim, garantir a atrelação desse produtor à empresa. Novos instrumentos de financiamento podem ser colocados em prática, facilitando a integração dos produtores descapitalizados dentro do mercado de biodiesel, criando novas oportunidades de geração de renda e superando as diferenças encontradas no meio rural (FINCO; RIBEIRO; BAILIS, 2014).

Outro aspecto importante se refere à escala produtiva. Os produtores com maiores escalas produtivas ficaram nos estratos de produtores mais eficientes. A área produtiva ainda continua sendo o principal determinante para o incremento da receita dos produtores. Entretanto, como colocado anteriormente, novas formas de 
gestão e de redução de custos são desenvolvidas pelos produtores, e estas precisam ainda ser aperfeiçoadas para uma maior evolução da atividade no segmento. A entrada do biodiesel na matriz energética cria mudanças institucionais nos setores em que este se desenvolve (GONÇALVES; FAVARETO; ABRAMOVAY, 2013), principalmente quando envolve integrar um segmento que antes não estava fazendo parte desse mercado, com o caso da agricultura familiar e sua produção de soja.

A experiência e os anos de estudo não foram variáveis tão significativas para a determinação da eficiência ou mesmo do resultado econômico dos produtores rurais. A produção de soja ocorre segundo a adoção de determinadas condições de produção, envolvendo pacotes fechados de insumos e sementes, além de técnicas de produção padronizadas. A assistência técnica prestada para os produtores assegura o cumprimento das exigências de qualidade e produtividade, reduzindo a possibilidade de perdas por ataques de pragas ou outros riscos. Em relação ao preço, este é determinado pelo mercado, principalmente pela cotação em bolsa e custos logísticos (ainda altos no Mato Grosso), com o bônus de R \$1,20 por saca adicionado a esse preço, o que garante uma pequena margem de segurança aos produtores em relação à garantia de renda, aspecto que o PNPB observou com sucesso.

\section{CONSIDERAÇÕES FINAIS}

Percebe-se dentro desse cenário que a finalidade do PNPB é alcançada (gerar emprego e renda para a agricultura familiar), mas de forma limitante. Como o objetivo do Programa inicial era diversificar a produção de matérias-primas para o biodiesel, criou-se uma expectativa que excedeu o real desenrolar do setor. O óleo de soja tomou conta do setor, e, com ele, apenas os produtores familiares que têm condições de produzir a oleaginosa acabam sendo beneficiados com o Programa. O limiar entre a viabilidade e o fracasso financeiro na produção de soja é muito estreito em razão do grande montante de capital investido, das variações de preço, dos ganhos de escala, e, na pequena propriedade, esses fatores tornam-se ainda mais agravantes pelo próprio tamanho da propriedade, que não permite diversificar a produção como complemento de renda.

Dessa forma, os produtores mais bem estruturados são inseridos sem muitas dificuldades no setor de fornecimento de matéria-prima, mas, com o aumento da demanda pelo biodiesel, será necessário que as empresas busquem mais produtores, o que, por sua vez, levará a novas estruturas de financiamento e viabilização da 
atividade, integrando ainda mais produtores; nesse sentido, existe um caminho a ser trilhado pela agricultura familiar dentro do mercado de biodiesel e da produção de soja. Novas formas de gestão e relacionamento com o mercado devem ser desenvolvidas para permitir a redução de custos e a melhor negociação dos produtos, melhorando a eficiência dos produtores rurais, pois nesse trabalho identificou-se um pequeno grupo ainda operando abaixo de uma condição satisfatória.

Novas ponderações se fazem necessárias sobre o fornecimento de matériaprima pela agricultura familiar. O plantio de soja, mesmo apresentando resultados econômicos para os produtores, ainda possui limitações e variações que podem impactar diretamente na capacidade de sustentabilidade da família. Novos estudos podem incluir variáveis ainda não estudadas neste trabalho, identificando novos aspectos do gerenciamento da atividade pelos produtores familiares, principalmente em relação à utilização de instrumentos de proteção de preço e de safra e uso de sistemas de informação.

Nota explicativa:

${ }^{1}$ A opção pela utilização do IPCA se deve porque o trabalho se buscou mensurar a renda obtida pelo produtor rural, portanto, esse índice contempla as variações de preços nos produtos de famílias com rendimento de 1 a 40 salários mínimos.

${ }^{2}$ Essa classificação foi arbitrada, visto que a DEA mensura a eficiência resultando em valores entre 0 e 1 , sendo 0 para ineficientes e 1 para eficientes.

\section{REFERÊNCIAS}

\section{AGÊNCIA NACIONAL DO PETRÓLEO. Anuário Estatístico Brasileiro} do Petróleo, Gás Natural e Biocombustíveis - 2014. 2014. Disponível em: $<$ http://www.anp.gov.br/?pg $=71976 \& \mathrm{~m}=\& \mathrm{t} 1=\& \mathrm{t} 2=\& \mathrm{t} 3=\& \mathrm{t} 4=\& \mathrm{ar}=\& \mathrm{ps}=\& \mathrm{cac}$ hebust $=1424442357675 \#$ Se_o4>. Acesso em: 20 fev. 2015.

BATALHA, M. O.; SILVA, A. L. Gerenciamento de sistemas agroindustriais: definições, especificidades e correntes metodológicas. In: BATALHA, M. O. (Coord.). Gestão agroindustrial: GEPAI: Grupo de Estudos e Pesquisas Agroindustriais. 3. ed. São Paulo, Atlas: 2011.

CASTRO, A. M. G.; LIMA, S. M. V; PINHEIRO, N. P. A Indústria de Produção de Biodiesel no Brasil. In: CASTRO, A. M. G; LIMA, S. M. V; SILVA, J. F. V (Org.). Complexo Agroindustrial de Biodiesel no Brasil: Competividade das Cadeias Produtivas de Matérias-Primas. Brasília, DF: Embrapa Agroenergia, 2010. 
DE JANVRY, A.; SADOULET, E. Rural poverty in Latin America determinants and exit paths. Food Policy, v. 25, p. 389-409, 2000.

DELGADO, Nelson Giordano. Política econômica, ajuste externo e agricultura. In: LEITE, S. (Org.). Políticas públicas e agricultura no Brasil. 2. ed. Porto Alegre: Ed. UFRGS, 2009.

FARGIONE, J. E.; PLEVIN, R. J.; HILL, J. D. The Ecological Impact of Biofuels. Annual Review of Ecology, Evolution, and Systematics, v. 41, p. 351-377, 2010.

FINCO, M. V. A.; RIBEIRO, V. S.; BAILIS, R. Biocombustíveis e a economia verde inclusiva: buscando o desenvolvimento regional sustentável na Amazônia legal brasileira. REDES, v. 19, n. 2, p. 130-153, 2014.

GONÇALVES, Y. K.; FAVARETO, A.; ABRAMOVAY, R. Estruturas sociais no semiárido e o mercado de Biodiesel. Caderno CRH, v. 26, n. 68, p. 347-362, 2013.

GRAHAM-ROWE, D. Agriculture: Beyond food versus fuel. Nature, v. 474, p. S6-S8, 2011.

GUimarÃES, Alberto Passos. A Crise Agrária. 2. ed. Rio de Janeiro: Paz e Terra, 1982.

HOUTART, François. A agroenergia: solução para o clima ou saída da crise para o capital? Petrópolis: Vozes, 2010.

JOHNSTON, B. F.; MELLOR, J. W. The role of agriculture in economic development. The American Economic Review, v. 51, n. 4, p. 566-593, 1961.

LIMA, S. M. V.; CASTRO, A. M. G. A Agroindústria de Óleo Vegetal para a Produção de Biodiesel. In: CASTRO, A. M. G; LIMA, S. M. V; SILVA, J. F. V (Org.). Complexo Agroindustrial de Biodiesel no Brasil: Competividade das Cadeias Produtivas de Matérias-Primas. Brasília, DF: Embrapa Agroenergia, 2010a.

LIMA, S. M. V.; CASTRO, A. M. G. O Agronegócio do Biodiesel e suas MatériasPrimas. In: CASTRO, A. M. G; LIMA, S. M. V; SILVA, J. F. V (Org.). Complexo Agroindustrial de Biodiesel no Brasil: Competividade das Cadeias Produtivas de Matérias-Primas. Brasília, DF: Embrapa Agroenergia, 2010 b.

OSAKI, Mauro; BATALHA, Mario Otávio. Produção de Biodiesel e Óleo Vegetal no Brasil: Realidade e Desafio. Organizações Rurais \& Agroindustriais, v. 13, n. 2, p. 227-242, 2011. 
PRADO JÚNIOR, Caio. A Questão Agrária no Brasil. 4. ed. São Paulo: Brasiliense, 1987.

SCHULTZ, Theodore W. A Transformação da agricultura tradicional. Rio de Janeiro: Zahar, 1965.

SILVA, José F. G. Estrutura agrária e produção de subsistência na agricultura brasileira. São Paulo: Hucitec, 1978.

\section{COMO CITAR ESTE ARTIGO:}

— RODRIGUES, Marcos. Agricultura familiar e produção de biodiesel: uma análise $Z$ no Norte Mato-grossense. RACE, Revista de Administração, Contabilidade e $\exists$ Economia, Joaçaba: Ed. Unoesc, v. 14, n. 3, p. 889-904, set./dez. 2015. Disponível em: <http://editora.unoesc.edu.br/index.php/race>. Acesso em: dia/mês/ano.

Rodrigues, M. Agricultura familiar e produção de biodiesel: uma análise no Norte Mato-grossense. RACE, Revista de Administração, Contabilidade e Economia, 14 (3), 889-904. Recuperado em dia/mês/ano, de http://editora.unoesc.edu.br/index.php/ race 